REVISTA ANDALUZA DE ANTROPOLOGÍA

NÚMERO 19: DÍAS EXTRAÑOS. CÓMO EL COVID-19 TRANSFORMA NUESTRA COTIDIANIDAD DICIEMBRE DE 2020

ISSN 2174-6796

[pp. 178-182]

https://dx.doi.org/10.12795/RAA.2020.19.12

\title{
OBITUARIO...
}

\section{CONVERSACIÓN EN TORNO A JOSÉ MARÍA MANJAVACAS RUIZ. IN MEMORIAM}

\author{
David Florido \\ Gema Carrera \\ Asociación Andaluza de Antropología (ASANA)
}

Concluimos este número con un obituario dedicado a José María Manjavacas, fallecido en abril de 2020. En 2018 entró a formar parte de la junta directiva de ASANA, en la que estuvo colaborando casi hasta el último momento en la tarea de difusión de actividades y noticias en las redes sociales. Es por eso que hoy lo recordamos en nombre de toda esta comunidad que formamos la Asociación Andaluza de Antropología, su junta directiva actual y las anteriores, y la Revista Andaluza de Antropología, con todo su nuevo equipo. Lo hacemos mediante una conversación a dos, ficticia pero muy real, en cuanto que permite la reconstrucción en primera persona de su trayectoria académica. Y las circunstancias mandan que coincida en este número titulado Días extraños. Cómo el covid-19 transforma nuestra cotidianidad. Imaginamos cómo nos hubiera enriquecido conocer también sus opiniones sobre este tema por su doble condición de personal sanitario y antropólogo. José María, te hubieran faltado manos que echar a tus colegas del Hospital Virgen del Rocío y habrías dado muchas claves necesarias en el análisis político y social de sus causas y consecuencias.

D.F: Aún puedo recordar cuando hablé con él la última vez. Me encontraba en Cádiz, saliendo del puerto, y me acordé de que me había contado que sus primeras actividades laborales y sus primeras inquietudes políticas, tuvieron ese escenario. Estábamos preparando uno de los programas radiofónicos de Caleidoscopio, en cuyo guion se 
planteaba hablar de los Carnavales, especialmente de su versión más popular y fresca, la que se despliega en la calle. Quería saber si podría colaborar en el programa vía telefónica, para que nos hablara de esta fiesta cuando se apodera de los barrios de Cádiz ese fervor transgresor que solo las sociedades milenarias atesoran casi de modo involuntario. Y me conmovió que, a pesar de su debilidad física, se mostraba dispuesto a colaborar. "Aunque me escuches así hoy - me dijo-, es porque acabo de pasar por un ciclo y estoy regular. Pero si me dices que el programa es para dentro de tres semanas, ya estaré recuperado, y puedes contar conmigo".

G.C: Sí, recuerdo bien que fui su entrevistadora en ese programa en que se trató el Carnaval, o mejor, los "carnavales de Cádiz", porque, como José María decía: "el carnaval de mi pueblo son muchos carnavales juntos". Fue el único de esa sección del programa dedicada al Atlas del Patrimonio Inmaterial, en el que tuvimos que hacer una entrevista telefónica en directo. Se resistía a aceptar esa imposición tecnológica marcada por la prisa y la inmediatez. Pero con la espontaneidad de la conversación tranquila y serena que tan bien manejaba, hablamos de la fiesta, uno de los temas que más tempranamente trató. Traspasó su apego al carnaval con una mirada antropológica casi desde el inicio de su carrera, porque ya había presentado aquel estudio colectivo en las XVI Jornadas de Antropología, en Granada: "Échate pa allá que vamos a cantar", la base de su primer documental etnográfico "Nos vemos en la calle", realizado junto a Abel Ajende y Carmen Guerrero en 2007. Me encantó. Entonces ya comprendí que me encontraba ante un defensor de esas arenas, las de la calle, siempre. Allí le gustaba tomar el pulso a la realidad. Me pregunto qué habría pensado ahora que nos encontramos en esta distopía actual: casi sin calle, sin carnaval.

D.F: Yo lo conocí siendo él estudiante de la licenciatura de Antropología, que terminaría allá por 2002 o 2003. Formaba parte de ese conjunto de personal de enfermería que acudió al calor de la licenciatura de segundo ciclo. Destacaba en las clases por la madurez en las intervenciones, por la seriedad y capacidad explicativa en la serena exposición de trabajos, por la consistencia de sus exámenes. Un estudiante sobresaliente, de los que hacen sentirse orgullosos, vanidosamente, a los profesores. Lo que para otros pudo ser un cálculo estratégico para su promoción personal, para él supuso un cambio radical en su trayectoria personal y profesional. La Antropología se adecuaba bien a la semilla fiera de rebeldía ante la injusticia social, que había surgido en sus primeras aventuras en el puerto de Cádiz.

Muy rápidamente se dio la ocasión para que conociéramos sus capacidades como investigador, en aquel trabajo sobre las asociaciones y entidades de drogodependientes en la provincia de Sevilla, que no gustó demasiado a la Administración Pública Andaluza. Su excelencia académica le dio acceso al programa nacional de Becas de Formación de Personal Investigador, dentro del Grupo de Investigación para el Estudio de las 
Identidades Socio-Culturales en Andalucía. Durante cuatro años, entre 2005 y 2009, desarrolló su investigación doctoral sobre los mecanismos de participación política en el ayuntamiento de Sevilla, a propósito de aquellos presupuestos participativos, instigados por el partido al que se sentía vinculado ideológica y sentimentalmente, Izquierda Unida. Su integridad académica quedó perfectamente reflejada en el análisis crítico, rotundo, de aquel experimento. Su estancia en el Centro de Estudios Sociales de la Universidad de Coímbra (2008) terminó por consolidar su interés en los movimientos sociales, la ciudadanía, por repensar el concepto de democracia. En los debates internos del grupo de investigación siempre me admiró su templanza, la capacidad para el buen discurrir y el buen discutir, desapegado de ciertas manías personalistas propias del colectivo.

G.C: Sí, es verdad, a mí también me admiraba escuchar sus intervenciones.... Especialmente apreciaba su forma de entender los múltiples campos que abordó, siempre desde la independencia, pero nunca de forma neutral. Valiente.

D.F: Entonces le pude conocer como compañero docente, entre 2008 y 2010, en la Universidad de Sevilla. Destacaba por trasladar a las aulas la experiencia y el conocimiento de distintas personas que podían plantear, ahora en el ámbito académico, normalmente clausurado, las problemáticas de la calle: sindicalistas, gente con experiencia política, del mundo de asociacionismo, algunas figuras históricas de la lucha social, expertos de otras áreas..., todos ellos convirtieron habitualmente sus clases en un foro abierto, para escándalo de algunos colegas.

Como la Universidad de Sevilla no le ofrecía posibilidades de continuidad, se decidió a dar un segundo salto decisivo, a la Facultad de Filosofía y Letras de la Universidad de Córdoba. Por aquel entonces colaboró en los talleres participativos de la investigación sobre los puertos andaluces - él, que llevaba el gen histórico del puerto de Cádiz en su biografía personal y política-. Cuando la cosa se ponía tensa en estos foros, siempre terciaba con su capacidad de mediación. Allí emergía a la superficie toda esa mar de fondo que había ido absorbiendo desde su juventud en asambleas y en cenáculos de militancia política, en el hospital, en su condición de técnico sanitario, en las guerrillas académicas. Fíjate que ese temple casi lo perdía cuando, en los momentos de convivencia más íntima, hablábamos de la necesidad de lograr el reconocimiento en el sistema de acreditación del profesorado, esa cruz. Y no era el mismo José María que se explicaba en sus publicaciones de Facebook, donde se desenvolvía con mayor sentido de propiedad de la palabra, de su pensamiento, más seguro de su posición.

Lo que más me ha admirado en Córdoba ha sido su capacidad de crear en torno a él y a un pequeño grupo de colaboradores el colectivo Etnocórdoba, que se convirtió en un foco atractor de investigaciones y en un elemento dinamizador de la ciudad. Fuimos a visitarlo en una salida de campo con los estudiantes de Antropología de Sevilla, hace dos años, para tratar el tema del turismo. Y allí replicó su modelo de enseñanza: exponer 
las líneas que enmarcan una problemática, siempre abierta, para a continuación dar la palabra a un activista del movimiento ciudadano, abriendo entonces un animado debate con los estudiantes, no solo sobre las dinámicas de turistificación, sino de cómo se podría incidir políticamente sobre ella. Córdoba, su hiriente situación por el avance descontrolado del turismo entendido como negocio que coloniza casas, barrios, modos de vida, fagocitando una cultura reducida a iconos mortecinos, era entonces su principal preocupación.

G.C: Precisamente, tuve la suerte de colaborar con esa experiencia, cuando me invitó al consejo asesor de Etnocórdoba, desde donde organizaba actividades y conferencias en torno al patrimonio cultural. Recuerdo aquel aula repleta, frente a frente, dialogando animadamente con ese alumnado despierto, locuaz, interesado. Ahí verifiqué su ilusión y su capacidad de cambiar cosas, de revitalizar la antropología y a la universidad desde abajo, creando ese grupo abierto a quienes compartieran "los valores y principios democráticos de libertad, igualdad y justicia social", llamando a colaborar desinteresadamente en un proyecto colectivo a quienes quisieran aportar su granito de arena. Una cantera de investigadores activos que aprendían ayudándose mutuamente fundamentados en " $e l$ pensamiento crítico, la inquietud intelectual, el rigor científico y el compromiso social". Lo mejor es que en todas y todos ellos ese proyecto continúa estando presente.

D.F: Y no lo tenía del todo fácil. Asumió lo que podría considerarse un caramelo envenenado: un análisis de las consecuencias e implicaciones del turismo en la ciudad, encargado por el grupo de Ganemos del Ayuntamiento de Córdoba. Recomiendo la lectura de la entrevista que sobre este tema le hicieron a José María en Cordópolis ${ }^{1}$. No es fácil proponer un análisis, con datos sobre el terreno, que diseccione las derivadas de un problema con tantas vertientes, cuando la corriente dominante en la ciudad tiene una posición favorable al turismo tan definida. Igualmente levantó esa su voz campanuda, sosegada, penetrante respecto a los valores patrimoniales de los patios, entonces ya un juguete roto de la política turística local - y decimos entonces porque desde la perspectiva post-Covid toda aquella sobreabundancia turística parece una broma macabra-. Resonaba fuerte su voz al defender el valor de las vecinas, de las macetas, de la experiencia de vecindad comunal que habían ido tejiendo la verdad de esos espacios íntimos, ya anegados por un público espectador cuya presencia hacía invisible sus valores culturales y cuyas ondas, las del turismo masificado, habían hecho ya imposible el mantenimiento de la experiencia de ciudad del vecindario.

G.C: Precisamente en ese momento trabajamos juntos en proyectos relacionados con nuestros intereses comunes en torno al patrimonio como identidad y como instrumento de transformación social en el contexto de dinámicas globales-locales que atraviesan

1. Disponible en: https://cordopolis.es/2017/11/19/jose-maria-manjavacas-la-mejor-oferta-turistica-decordoba-es-que-la-ciudad-siga-siendo-como-es/ 
cualquier sociedad hoy. José María realizó entonces un nuevo documental dedicado a los patios de Córdoba: "Patios y Gentes". No olvidaba, una vez más, cuál era el sujeto colectivo que debía tomar la palabra y hacerse sentir en la toma de decisiones en torno a este patrimonio Inmaterial "turistizado y mercantilizado". Reivindicaba con contundencia la necesidad de una mayor presencia del asociacionismo vecinal y ciudadano en el conjunto de temas de la ciudad y, sobre todo, el tratamiento político del patrimonio cultural y sus usos, así como el necesario debate, propuestas y toma de decisiones en torno a la política turística local y sus impactos en la fiesta de los patios de Córdoba. Todo ello quedaría reflejado en las conclusiones del Congreso de Patios de Córdoba del que fue co-director científico en febrero de 2019.

D.F: Mirando retrospectivamente su trayectoria académica, persiste su huella de investigación comprometida: sobre luchas sociales, sobre las vías para una ciudadanía democrática, sobre el patrimonio como herramienta de participación política, o sobre la reivindicación de formas de vida resilientes ante el avance de las dinámicas homogeneizadoras del mundo contemporáneo. Todo ello estaba condensado en su último encargo: el informe técnico sobre los valores patrimoniales del Carnaval de Cádiz, que pudo explicar - ay, ya esa voz ajada-, en uno de los entreactos del concurso del Teatro Falla en su edición de 2019.

G.C: Sí, recuerdo cuando aceptó aquel difícil encargo. Nadie mejor que él podía haber enfrentado este reto con todas las contradicciones que le planteaba. Sabía que la intención era declararlo Patrimonio Inmaterial de la Humanidad y conocía muy bien las consecuencias que tienen estas activaciones en las expresiones y lugares galardonados con la distinción de ser incluidos en las listas de UNESCO. Ya lo había sufrido en Córdoba con los Patios. Pero ahora le tocaba a sus carnavales, a su gente, a Cádiz. Reivindicaría la capacidad de los carnavales para ser una herramienta de lucha colectiva para reclamar su "utopía identitaria". Por ello, instó de nuevo a la gente de Cádiz a ser un sujeto activo, capaz de trascender la propaganda político-mediática que acompaña a estos procesos y a participar en la toma de decisiones.

D.F: Yo lo que aprecié en esa intervención es..., de nuevo, la germinación de esa semilla de rebeldía, que nos traslada a los versos autobiográficos de Don Antonio Machado: llevabas en tu sangre gotas de sangre jacobina, aunque tu verso brotaba de manantial sereno. 